Int. J. Dev. Biol. 57: 255-263 (2013)

doi: $10.1387 / \mathrm{ijdb} .130015 \mathrm{fg}$

\title{
Effect of endogenous and exogenous hormones on testicular cancer: the epidemiological evidence
}

\author{
FABRIZIO GIANNANDREA ${ }^{1}$, DONATELLA PAOLI ${ }^{1}$, IRENE FIGÀ-TALAMANCA ${ }^{2}$, \\ FRANCESCO LOMBARDO ${ }^{1}$, ANDREA LENZI ${ }^{1}$ and LOREDANA GANDINI ${ }^{1}$ \\ ${ }^{1}$ Department of Experimental Medicine, Laboratory of Seminology - Semen Bank, University of Rome "La Sapienza", Rome, \\ Italy and 'Department of Public Health and Infectious Diseases, University of Rome "La Sapienza", Rome, Italy
}

\begin{abstract}
Testicular cancer is the most common type of malignancy in men aged 15-40 years. Although its incidence has increased over the past $\mathbf{4 0}$ years in most countries, the reasons for this rise are unclear. It has been suggested that a relative excess of endogenous estrogens during prenatal life and/or later exposures to various occupational and environmental estrogenic chemicals such as organochlorine compounds may play a causal role in the etiology of testicular cancer, but the issue is still open to further research. The purpose for this review is to summarize the epidemiologic literature about hormonal factors, endogenous hormones and environmental xenoestrogens, and testicular carcinogenesis. Future studies need to (a) consider the possible synergistic effect of exposure to environmental xenoestrogens and sex hormones, (b) focus on the most vulnerable life stages of exposure to endocrine disruptors and testicular cancer risk, (c) assess the possible additive role of androgen secretion occurring during puberty in tumor progression, and (d) consider more systematically gene-environment interactions.
\end{abstract}

KEY WORDS: testicular cancer, estrogen, androgen, xenoestrogen, organochlorine compound

\section{Introduction}

Testicular cancer (TC) is the most common type of malignancy in men aged $15-40$ years. Approximately $98 \%$ of all testicular malignancies are germ cell tumors. Although there are a number of histologic types of TC, around $55 \%$ may be classified for descriptive purposes as classic seminomas, $44 \%$ as nonseminomas (embryonal carcinomas, teratomas, yolk sac tumors, choriocarcinomas) and $1 \%$ as spermatocytic seminomas (Almstrup et al., 2006, McGlynn \& Cook, 2009). The incidence of TC has more than doubled worldwide over the last 40 years in several populations (Liu et al., 2000, Purdue et al., 2005, Bray et al., 2006). The reasons of this rise are not entirely clear. The most consistently identified factor associated with TC is cryptorchidism, which increases a man's risk of TC development by nearly 5 -fold (Dieckmann and Pichlmeler, 2004). Familial TC is also an established risk factor for TC risk. Studies have estimated that brothers of TC patients have 8-10 fold increased risk of having TC, whereas the fathers/sons have 4-6 fold increase in risk (Dong et al., 2001). Only 1-2 \%, however, of TC patients report a first degree relative also affected by TC (Lutke Holzik et al., 2004).

Evidence of incidence peak of TC among young adults sug- gests that causal factors operate during embryogenesis or early in life (Bray et al., 2006). One theory attributes it to the increase in endogenous estrogen levels during prenatal life and/or later exposures to various occupational and environmental estrogenic chemicals, termed endocrine-disrupting chemicals (EDCs) (Sharpe and Skakkebaek, 1993, Skakkebaek et al., 2001, Foster and Agzarian, 2008). According to this hypothesis, these exposures are also risk factors for other male reproductive disorder, such as cryptorchism and impaired sperm quality. Recently, it has been suggested that postnatal exposures might also increase the risk of developing TC, and that androgen secretion during puberty might be involved in TC progression (James, 2010, Trabert et al., 2011). The present review of published studies, mostly epidemiological, aims to identify risk factors related to TC, with a particular emphasis on endogenous and exogenous hormonal factors that constitute a risk of disease development. It may also serve to identify gaps in knowledge and recent research needs for TC and

\footnotetext{
Abbreviations used in this paper: AR, androgen receptor; DES, diethylstilbestrol; EDCs, endocrine disrupting chemicals; ER, estrogen receptor; $\mathrm{HCB}$, hexachlorobenzene; PCBs, polychlorinated biphenyls; p,p'-DDE, dichloro-diphenyl-trichloroethylene; $\mathrm{TC}$, testicular cancer.
}

\footnotetext{
*Address correspondence to: Fabrizio Giannandrea. Department of Experimental Medicine, Laboratory of Seminology - Semen Bank, University of Rome "La Sapienza", P.le Aldo Moro No. 5, I-00185 Rome, Italy.Tel. +39-06-4991-2682; Fax. +39-06-4991-2771. E-mail: fabrizio.giannandrea@uniroma1.it
} 
could point out the possible interactions between hormonal and environmental factors.

\section{Testicular germ cell development and carcinogenesis}

One widely accepted notion, based on histopathological observations, is that TC arises from carcinoma in-situ (CIS) cells which are presumed to derive from primordial germ cells that escaped normal differentiation into spermatogonia in utero (Skakkebaek et al., 1987). CIS cells are morphologically very similar to gonocytes, and similarly to gonocytes, they express a number of common immunohistochemical markers, such as placental-like alkaline phosphatase (Almstrup et al., 2006), a classical marker of primordial germ cells, and KIT, the receptor for stem cell factor. The mechanism by which CIS evolves to a malignant form has not yet been explained in detail. The analysis of the CIS phenotype has provided strong evidence that developmental arrest in the differentiation of the early germ cell lineage is a core pathogenetic event leading to neoplastic transformation, i.e. into CIS. Differentiation of gonocytes into infantile spermatogonia is a gradual process which begins around 20 weeks of gestation and often continues in the early postnatal period until approximately 6-9 months of age, when the immunohistochemical markers that are shared by primordial germ cells/gonocytes and CIS are finally down-regulated in the last remaining germ cells (Almstrup et al., 2006). Persistent expression of these markers later in childhood is not common. The initiation of the neoplastic transformation is most likely triggered by a disturbance in the embryonic, fetal or early postnatal microenvironment of differentiating germ cells.

Gonadal microenvironment of developing germ cells is very tightly regulated and sensitive to hormones and paracrine factors. Even a slight disturbance in the hormonal balance may topple the delicate balance and delay or arrest the differentiation of primordial germ cells or gonocytes into infantile pre-spermatogonia. It has been suggested that low or high androgen level or excessive estrogens exposure, or an exogenous hormonal imbalance (e.g. environmental exposure to one or more environmental endocrine disrupters) might be responsible of the arise of these cells (Almstrup et al., 2006). The disturbance may also be caused by a genetic defect (e.g. in the androgen insensivity or other intersex syndromes). Hormonal imbalance in the cellular microenvironment may lead to errors in cell division and progressive genomic aberrations that lead to further genomic instability and formation of transformed 'pre-CIS cells'. The invasive progression of TC is most probably triggered by the drastic change of testicular hormone production associated with puberty. This might explain the increase in the age-specific incidence of TC after puberty (Richiardi et al., 2007).

\section{Role of estrogens in testicular carcinogenesis}

Estrogens have a crucial role in both male and female reproduction. The physiological role of estrogens is multiple and not all are yet known. Estrogens are steroid hormones that bind to intracellular estrogen receptors $E R \alpha$ and $E R \beta$ to activate gene transcription via estrogen-response elements located near the promoter regions of estrogen-responsive genes (Martin et al., 2008). Carcinogenic effects of perinatal exposure to environmental estrogen Diethylstilbestrol (DES) on the accessory sex glands in male experimental animals have been described in mice, rats, and hamsters. Prenatal
DES exposure of mice also induces TC (particularly of the rete testis) and non-neoplastic lesions in the testes and epididymis. In 1993, Sharpe and Skakkebaek proposed to comprise impaired spermatogenesis, male reproductive tract abnormalities such as hypospadias and cryptorchidism, and TC into a common underlying syndrome with a common aetiology resulting from the disruption of embryonic programming and gonadal development during fetal life, known as the Testicular Dysgenesis Syndrome (TDS) (Skakkebaek et al., 2001, Sharpe, 2003). The basic idea is that TC is already initiated in utero during embryogenesis. According to this hypothesis, the development of the gonads is affected by a relative excess of estrogens during early pregnancy. In particular, it is thought that, following endocrine disruption, some of the primordial germ cells lose track of their normal development. These cells fail to enter the normal pathway to prospermatogonia and finally become premalignant cells that may develop into CIS cells after birth. It is believed that these cells stay in a dormant stage during childhood (Richiardi et al., 2007). Only after the endocrine stimuli of puberty do they resume activity, replicate and spread within the seminiferous tubules. Triggered by other unknown cofactors, $\mathrm{CIS}$ cells may then develop into a complete cancer. The estrogen excess may arise secondary to the exogenous administration of hormones, or it may be secondary to endogenous hormonal imbalances. As recently suggested, it might also result from exposures to various occupational and environmental estrogenic chemicals (EDCs) (Joffe, 2001).

Several systematic reviews of the literature on the association between exposure to endogenous and exogenous estrogens and the disorders thought to belong to the TDS have been published, but only three provided a quantitative summary estimate of this association (Toppari et al., 1996, Storgaard et al., 2006, Martin et al., 2008). Storgaard et al., (2006) rewiewed 22 epidemiological studies exploring prenatal estrogen and the risk of TC. Indicators of fetal estrogen exposure included direct measurements, recorded intake of hormones (DES, oral contraceptives and estrogens), and some environmental exposures.

The nine studies included in the meta-analysis of TC provided by Martin et al., 2008 showed an increase in risk for TC associated with prenatal exposure to DES. However, this meta analysis was unable to produce evidence that such effects were associated with environmental estrogens or even accidental use of oral contraceptives during pregnancy.

Since prenatal estrogen levels during pregnancy are difficult to assess, several epidemiologic studies have investigated the association between a number of 'proxy' of prenatal endogenous estrogen exposures and TC risk, including birth order, gestational duration, maternal age, twin pregnancies, nausea during pregnancy, bleeding during pregnancy, birth weight, neonatal jaundice, etc. (Garner et al., 2005, Storgaard et al., 2006).

Characteristics of the newborn, such as birth weight, can act as surrogates for the maternal in utero environment and associated estrogen exposures. A comprehensive review of the findings of seven studies examined the effect of birth weight and TC (Garner et al., 2005): four found no association, and 3 found an increased risk among low birth weight children of approximately 1.5-2-fold. At this point, no clear conclusions can be drawn about the association between birth weight and TC risk, although the association may be mediated by intrauterine growth retardation. A more recent meta-analysis has estimated a pooled odds ratio (OR) for low birth 
weight of 1.01 (95\% Cl: 0.73-1.40) from registry-based studies (Richiardi et al., 2007).

Excess of endogenous estrogens can cause nausea during pregnancy. Findings are conflicting and, at this time, no definitive conclusions can be drawn about the association of nausea in pregnancy and TC. It should be noted that the measurement of nausea in pregnancy is difficult and usually requires the mother to remember an event that occurred 30 years ago (Garner et al., 2005). The meta analysis provided by Cook et al., (2009) included 12 studies that generated a summary estimate of $1.15(95 \% \mathrm{Cl}$ 0.92-1.45).

Several studies have indicated that children of mothers with high parity have a decreased risk of TC when compared to children of mothers with one child. It has been previously suggested that maternal endogenous estrogen levels are higher in first pregnancies as compared to subsequent ones (Richiardi et al., 2007). Birth order is easily assessed and the results from all studies are consistent with an elevated risk among first-born sons. Since elevated levels of estrogens in utero have been found to increase $\mathrm{TC}$ risk, firstborn sons may be at increased risk as a result of their increased exposure to estrogens in utero. More recently, a Swedish study reported a significant trend of TC risk decreasing both with increasing birth order and sibship size in men born before 1960 (Richiardi et al., 2004). The meta-analysis of birth order and sibship size provided by Cook et al., (2009) evidenced an inverse relationship with $\mathrm{TC}$. It was suggested that parental subfertility in TC cases and not elevated maternal hormone levels alone are more likely explain the results (Cook et al., 2009).

Several twin studies have examined the effect of endogenous hormones on TC risk and in all studies a higher risk was found for dizygotic twins, but not for monozygotic twins (Cook et al., 2010). It is thought that dizygotic twin pregnancies have higher maternal circulating estrogen levels than monozygotic pregnancies. Swerdlow et al., noted an odds ratio (OR) of 1.5 (95\% confidence interval [Cl] 1.1-2.2) for TC in dizygotic twins compared to monozygotic twins (Swerdlow et al., 1999). Braun et al., (1995) reported a significant 2-fold increase in risk among dizygotic twins compared to Swedish population levels. Among studies evaluated by Storgaard et al., (2006), risk of TC was more frequent among first-born sons and dizygotic twins. The meta-analysis of twinning and TC risk provided by Cook et al., (2010) included 11 studies, which produced a summary risk estimate of $1.22(95 \% \mathrm{Cl} 1.03-1.44)$. These findings suggest that TC may have an "environmental" cause due to a component acting in utero. However, twinning itself is, to a substantial extent, genetically determined, and more research is needed to clarify the contribution of genetic factors related to this increase.

\section{Role of androgens in testicular carcinogenesis}

The major androgens, testosterone and dihydrotestosterone (DHT), play key roles in testicular gland growth and development. Testosterone is produced mainly by testicular Leydig cells and is converted by type II $5 \alpha$ reductase in the prostate to DHT. Compared to testosterone, DHT has about 2.5-fold stronger affinity for the androgen receptor (AR) and is more potent than testosterone to stimulate virilization of the male external genitalia. AR regulates transcription of androgen-responsive genes essential for growth, appearance of masculine traits, secondary male characteristics and spermatogenesis (Culig et al., 2000). Exposures to androgens acting during puberty could be of particular importance in the onset of TC. Puberty is a period of high cellular replication; spermatogonia, which remain rather inactive during infancy and childhood, start undergoing meiosis to form spermatocytes and sperm cells, stimulated by the surge of steroid and peptide hormones. It has been recently hypothesized that low postnatal testosterone/gonadotrophin ratios might predisposes to TC (James, 2010). This theory is in agreement with the widespread secular decline in men's testosterone concentrations. Moreover, low fertility reported before diagnosis in many patients with TC, is commonly associated with low testosterone/gonadotrophin ratios (James, 2010).

In the literature, the role of androgen levels and TC risk has received less attention than exposure to endogenous and exogenous estrogens. Stimulated by racial differences in TC risk, several studies compared androgen levels in black and white mothers. Findings of greater testosterone levels in black mothers led to the hypothesis that lower risk for TC in black men may be caused by greater maternal testosterone levels (McGlynn et al., 2005).

The lower incidence of TC in African Americans than that observed among white Americans (McGlynn et al., 2005) could also be explained by a difference in the length of the polymorphic polyglutamine stretch in the androgen receptor, which is on average shorter among Africans and possibly more efficient in activating transcription (Sartor et al., 1999).

Since endogenous androgen levels during puberty and early adulthood are difficult to assess, possible surrogates of increased androgen levels, such as male pattern baldness and severe acne, have been used in studying the relationship of endogeneous androgen levels and TC. Several studies indicate that DHT, is the principal mediator of androgen-dependent hair loss and severe acne (Hamilton, 1946, Balducci et al., 1996). Baldness and severe acne, have been inversely associated with risk of TC (Hamilton, 1946, Depue et al., 1983; Petridou et al., 1997). In a case-control study of 97 TC cases and 198 age-matched controls in Athens, Greece, Petridou et al., (1997) reported an inverse association of TC with baldness. In a case-control study of 108 TC cases in men aged 16-30 years and 108 age-matched neighbourhood controls in Los Angeles County, Depue et al., (1983) also reported an inverse association between TC and of severe acne around the time of puberty.

In the Trabert et al., study (2011), cases were significantly less likely to report hair loss than controls (OR $0.6 ; 95 \% \mathrm{Cl} 0.4-1.0$ ). History of severe acne was also inversely associated with TC (OR $0.5 ; 95 \% \mathrm{Cl} 0.3-0.9)$. Therefore, it is plausible that the gonadal dysfunction contributing to increased DHT in men with severe acne or male pattern baldness may also contribute to decreased TC risk, but further studies are required to more fully understand the role of androgens in TC.

\section{Polymorfism in genes involved in sex hormone metabolism}

The effects of estrogen are now known to be mediated by estrogen receptor (ER)- $\alpha$ and - $\beta$ receptor subtypes. Both $E R$ isoforms are coded by two different genes on different chromosomes,6q25 and 14q23-24, and are expressed differently in the normal testis (Pais et al., 2003). ER $\alpha$ is expressed in the efferent ducts but has not been found in the testicular or somatic germline, while $E R \beta$ is present in spermatogons, spermatocytes, spermatids and the so- 
matic cells. $E R \beta$ is thus considered the main mediator of oestrogen action, which we know to be highly important for the survival and development of the male germline. This receptor provides a possible mechanism of action through which environmental oestrogens could affect reproductive function. For this reason, some studies have evaluated ER gene polymorphisms and their association with infertility, cryptorchidism and TC. A link between two ER gene polymorphisms and azoospermia or severe oligozoospermia has recently been demonstrated, although as yet there are few studies of the correlation between the two polymorphisms described for the ER $\beta$ gene, Alu I and Rsa I, and TDS (Pais et al., 2003). Current studies, however, do not support an important role for the ER gene in conferring susceptibility to TC (Heimdal et al., 1995, Ferlin et al., 2010).

The classical genomic actions of androgens are mediated by the androgen receptor (AR). Association of androgen receptor polymorphisms with increased TC risk have been recently investigated in several studies since there is emerging evidence that polymorphic genes may modulate the endogenous androgens or environmental toxicants effecting the TC risk (Lutke Holzik et al., 2004).

Expression of the AR has been demonstrated in human CIS cells and may thereby respond directly to androgens following puberty (Rajpert-De Meyts et al., 2002). Thus, it seems plausible that AR action could influence the malignant potential of testicular germ cells in both the fetal and postpubertal periods and consequently the androgen receptor gene may be the most obvious candidate for a possible association of a polymorphism with TC.

Functional variants in the AR gene are thought to be implicated because of the greatly increased TC risk among men with AR mutations. These might disrupt AR function sufficiently to cause androgen insensitivity and high levels of circulating testosterone and estrogen. Mutations of the androgen receptor (AR) gene could induce various forms of androgen insensitivity, causing micropenis, hypospadia, cryptorchidism and impaired spermatogenesis. The AR gene has an important role in the development and maintenance of the male phenotype and spermatogenesis. Insensitivity to androgens is also a known risk factor for TC. The AR gene has two polymorphous sites on exon 1, which have a different number of CAG and GGC triplets determining the different lengths of the polyglycine and polyglutamine tracts of the $\mathrm{N}$-terminal transactivation domain (TAD) of the AR protein (Rajpert-De Meyts et al., 2002). Males have one copy of the AR, located at Xq11-12, and observational studies consistently report higher levels of serum testosterone and estradiol among men with longer repeat lengths.

Epidemiological studies have demonstrated that the different length of CAG triplet repeats may have a role in the onset of TC (Lutke Holzik et al., 2004).

In fact, Africans have fewer CAG repeats and a lower incidence of TC than Caucasians. One possible explanation could be that the average shorter length of the polymorphic polyglutamine stretch in the androgen receptor among Africans may be slightly more efficient in activating transcription (Sartor et al., 1999). However, there are only four studies on the link between CAG length and TC (RajpertDe Meyts et al., 2002, Giwercman et al., 2004; Garolla et al., 2005; Davis-Dao et al., 2011). Rajpert-De Meyts et al., (2002) found no difference in the distribution of (CAG)n between the subjects with TC and controls, no association of (CAG)n and the tumor type and no association with severity of the disease. Garolla et al., (2005) found that the combination $C A G=20 / G G C=17$ was significantly more frequent in patients with TC than in controls. Giwercman et al., (2004) reported that the proportion of males with the longest CAG repeats was significantly lower among patients with pure seminomas compared with non-seminomas and controls, whereas the median CAG length was higher if the tumour was metastasing at diagnosis. Davis-Dao et al., (2011) found risk of seminoma to be associated with shorter CAG repeats. Only one study has examined whether the TC risk associated with hormonally active compounds was modified by androgen receptor CAG. It found no evidence that the risk of TC associated with p,p'-DDE was modified by the number of CAG repeats (Biggs et al., 2008). Several published case-control studies found that longer CAG repeats were associated with risk of nonseminoma. Further association studies are needed to confirm associations of shorter AR CAG repeats with seminoma risk, longer AR CAG repeats with nonseminoma risk, and epidemiologic investigation of potential joint effects of functional $A R$ variants and exposure to hormonally active compounds of both endogenous and exogenous origin.

As for prenatal estrogen exposure, the mechanisms behind these associations are yet unexplained. Future aetiological studies on TC should take postnatal exposures to androgens during puberty into account.

\section{Risk factors associated with possible hormonal mechanisms}

The results of a variety of epidemiologic studies have led to suggestions for several risk factors that may be related to a hormonal mechanism. These risks include dietary factors, ethnicity, subfertility, and anthropometric measures.

\section{Diet and nutrition}

Diet can influence circulating hormone levels, by affecting steroid hormones status. In a study reported by Dorgan et al., (1996), the combination of a high-fat, low-fiber diet increased both total testosterone (by $13 \%$ ) and testosterone bound to sex hormonebinding globulin (SHBG; by $15 \%$ ) in the plasma as well as urinary testosterone excretion (13\%), compared with a low-fat, high-fiber diet. However, urinary excretion of estrone and estradiol was lower. High intake of fat has been associated with increased risk of TC (Armstrong and Doll, 1975, Sigurdson et al., 1999), a result consistent with findings also concerning other hormone related cancers such as breast, prostate, and ovary (Armstrong and Doll, 1975, Giovannucci et al., 1993, Sigurdson et al., 1999). In their ecological study, Armstrong and Doll (1975) found that international incidence rates of TC in 1960-1966 in the 35-65-year-old age group correlated strongly with consumption of total fat $(r=0.76)$. Other ecological studies found similar associations with dietary fat and high calorie intake (Ganmaa et al., 2002; Paulozzi, 1998, Giannandrea, 2009). Sigurdson et al., (1999) found that high fat consumption 1 year before diagnosis of TC was associated with an increased risk of TC. TC was also associated with consumption of dairy products (Decarli and La Vecchia, 1986, Davies et al., 1996, Ganmaa et al., 2002, Garner et al., 2003, Stang et al., 2006). Dairy products, particularly milk and cheese, contain the female sex hormones estrogen and progesterone (Ganmaa et al., 2002). Garner et al., (2003) found that high dairy product intake 2 years before interview was associated with an increased risk of TC. Davies et al., (1996) also observed in a case-control study of diet and TC, that the cases had consumed significantly more milk during adolescence than controls. In Stang et al., study (2006), 
adolescent dairy product consumption (with the exception of yoghurt) and especially milk was a risk factor for TC, especially for seminoma. They found an increasing risk for seminoma with increasing milk fat intake and an even stronger association between galactose consumption and seminoma especially in the younger men (age 15 to 34 years). In an ecological study of TC rates in 42 countries and their dietary practices, Ganmaa et al., (2002) found that cheese, animal fats, and milk were highly correlated with the incidence of TC at ages 20-39. The correlation coefficient was highest when calculated for cheese consumed during the period 1961-1965 (maternal or prepubertal consumption). Furthermore, stepwise multiple regression analysis revealed that milk + cheese (1961-1965) were associated significantly with the incidence of TC (Ganmaa et al., 2002).

The idea that the diet of children might be associated with TC risk originated from several epidemiological observations of constantly increasing incidence of TC since the beginning of the 20th century with the only major interruption in this trend occurring for men born during World War II or immediately thereafter, when food availability had been dramatically reduced (Aschim et al., 2005); it is also well-known from both animal and human studies that dietary restriction during early life does in general reduce adult cancer

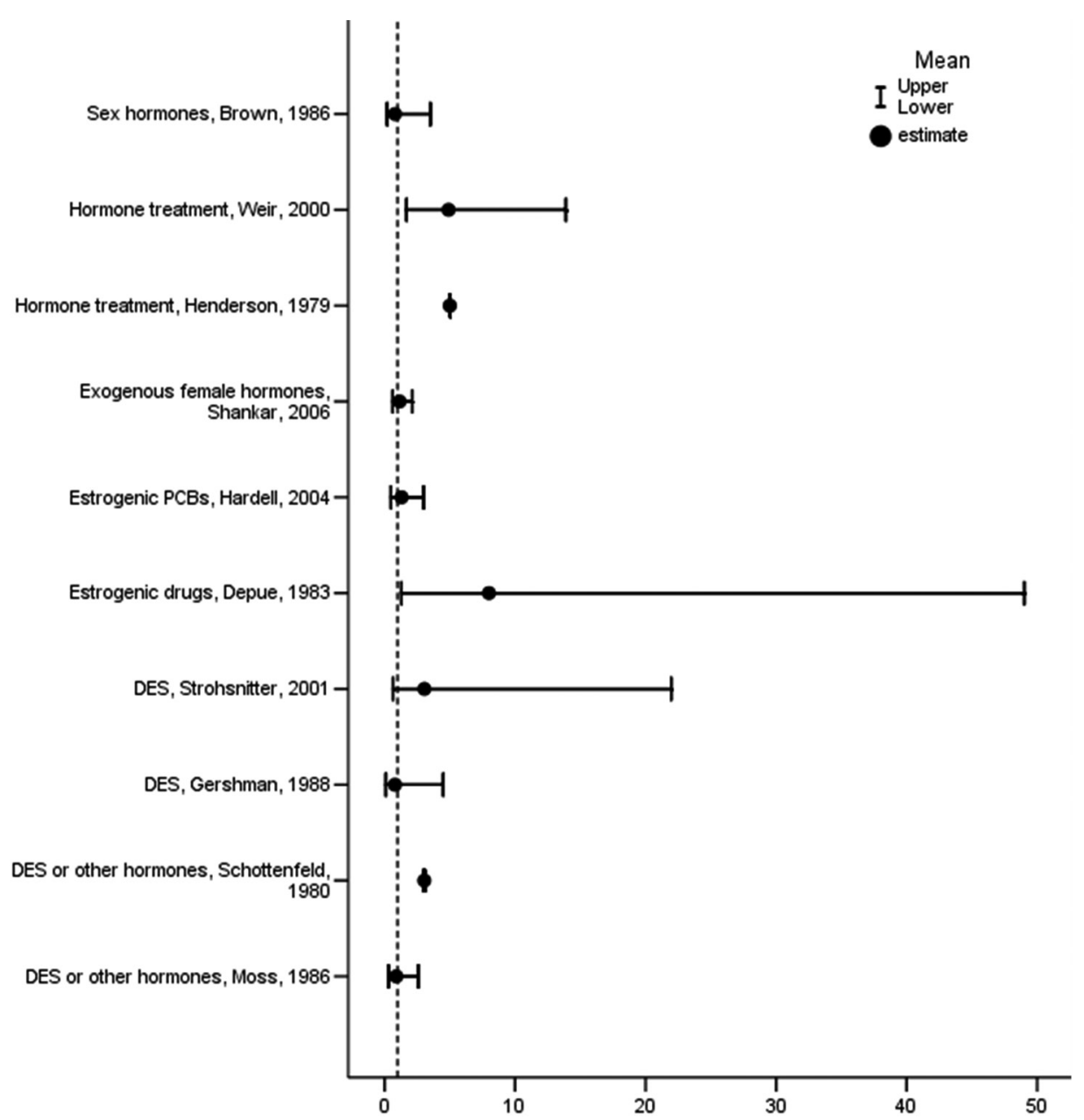

Fig. 1. Summary of studies on the risk of testicular cancer and prenatal exposure to estrogenic agents in $\mathbf{1 0}$ epidemiological studies. Estimated $\mathrm{OR}$ and $95 \% \mathrm{Cl}$. risk (Frankel et al., 1998, Uauy and Solomons, 2005); moreover, it has been proven that poor and nutritionally underprivileged populations such as African, including U.S. blacks, and Asian populations experience a lower TC risk than more affluent people (Dieckmann et al., 2004).

\section{Height}

A number of studies have reported that increased adult height may be a risk factor for TC, thereby suggesting that factors related to adult height may also be related to risk of these tumors (Richiardi et al., 2007, Dieckmann et al., 2008, Lerro et al., 2010). Dieckmann et al. (2008) found that very tall men $(>195 \mathrm{~cm})$ carried a TC risk of OR: 3.35 (95\% confidence intervals $(\mathrm{Cl})$ : 2.88-3.90; adjusted). In the STEED Study, there was a statistically significant increased risk of TC associated with greater height, and this association was particularly evident in men with seminomas (Lerro et al., 2010). As final adult height is largely determined during the first 2 years of life, it may be postulated that high calorie nutrition after birth could have a role in TC pathogenesis (Dieckmann and Pichlmeier, 2004). In addition, as final adult height is strongly dependent on testis sex steroids (Veldhuis et al., 2005) a correlation between height and TC risk may suggest that androgen secretion during puberty might be involved in TC progression.

One further height-related factor may be insulin-like growth factor (IGF) and the IGF pathway. Increased serum IGF-1 concentrations were associated with increased height has also been observed in several studies. However, contrary to expectation, in the study of Chia and coworkers (2007), there was a suggestion of a reduction in seminoma risk associated with high IGF-1 concentrations, particularly among shorter men. Thus, the relations among height, IGFs, and risk of TC are likely to be complex and not easily explained.

\section{Ethnicity}

The incidence of TC in African Americans is only one quarter of that observed among white Americans (McGlynn et al., 2005). Findings of greater testosterone levels in black mothers led to the hypothesis that lower risk for TC in black men may be caused by greater maternal testosterone levels. Another possible explanation could be a difference in the length of the polymorphic polyglutamine stretch in the androgen receptor, which is on average shorter among Africans and possibly more efficient in activating transcription (Sartor et al., 1999). Thus, the incidence of TC among native African populations is similar to that of African American counterparts, and by contrast they have a very high risk of prostate cancer, suggesting a possible role of higher testosterone levels in utero or other genetic predisposition (McGlynn et al., 2005). The risk of native African populations has not 
changed by much with migration to a new environment. Differences in incidence persisting after migration argue in favour of genetic rather than exogenous risk factors.

\section{Subfertility}

It is established that there exists a clear epidemiologic association between TC and subfertility. Although low fertility reported before diagnosis in many patients with TC is commonly associated with low testosterone/gonadotrophin ratios (James, 2009), the exact etiology of such a connection is still debated (shared susceptibility and/or shared environmental risk factors). A recent meta-analysis of seven case-control studies that included 4,954 participants revealed an overall statistically significant association between subfertility and increased risk of TC (summary RR: 1.68, $95 \% \mathrm{Cl}$ 1.22-2.31) (Peng et al., 2009). Richiardi and Akre (2005) in a case-control study of about 3000 cases and 9000 controls compared the fertility of brothers and sisters of TC patients with the fertility of brothers and sisters of population controls (Richiardi and Akre, 2005). Brothers of TC patients tended to father a smaller number of children and had a lower proportion of unlike-sex twins. Recently, Altieri and Hemminki (2007) reported that having five or more siblings vs none (RR $0.71,95 \% \mathrm{Cl}, 0.62-0.82)$ was associated with strong decreased risk of TC.

These results, also taken in the context of studies on subfertility and TC, indicate that these two conditions tend to cluster in families, implying that they may share early environmental exposures and inherited susceptibility. One implication of shared inherited susceptibility is that familial risks might be higher among TC patients with a known history of subfertility. Based on the latter consideration, the results of an association between the 'gr/gr' deletion and TC risk become of great interest (Repping et al., 2003). The "gr/gr" deletion in the $Y$ chromosome has been found to be associated with subfertility and TC (Nathanson et al., 2005). Similartypes of mutations, namely those associated with subfertility, are probably candidate mutations to be investigated in relation with $\mathrm{TC}$ risk.

\section{Exogenous hormones and environmental xenoestrogens}

Xenoestrogens are part of a group of synthetic and naturally occurring agents termed endocrine disruptors because of their capacity to perturb normal hormonal actions. A number of synthetic and environmental chemicals have been implicated as exogenous hormones possessing endocrinedisrupting properties.

\section{Diethylstilbestrol (DES)}

DES is a highly potent synthetic estrogen agonist that was prescribed to more than 5 million pregnant women in 1940-1960 to prevent abortions and pregnancy-related complications (Palmlund, 1996). Evidence later showed that maternal exposure to DES during early pregnancy increased the risk of male genital defects, cryptorchidism, and impaired sperm quality in the male offspring (Strohsnitter et al., 2001), but epidemiological studies have failed to show a statistically significant relationship between DES exposure and TC (Fig.1). The nine studies included in the meta-analysis of TC provided by Martin et al., (2008) showed an increase in risk for TC associated with prenatal exposure to DES that was not statistically significant. A previous meta-analysis was that by Strohsnitter et al., (2001) who examined DES related TC in four different cohorts of 1709 exposed and 1904 non-exposed men, finding an elevated not statistically significant risk of TC in the exposed group (RR 3.05; 95\% Cl 0.65-21.96).

\section{Organochlorine compounds}

Persistent organochlorine compounds, including polychlorinated dibenzo-p-dioxins, DDT, HCB, and PCBs are lipophilic ubiquitous environmental contaminants that were widely used in industrial and consumer products for decades until the late 70s (Cook et al., 2011). These compounds mimic the actions of estrogen by binding to estrogen receptors or have antiandrogenic effects (Phillips and Tanphaichitr, 2008). In the last decades concern has been raised about

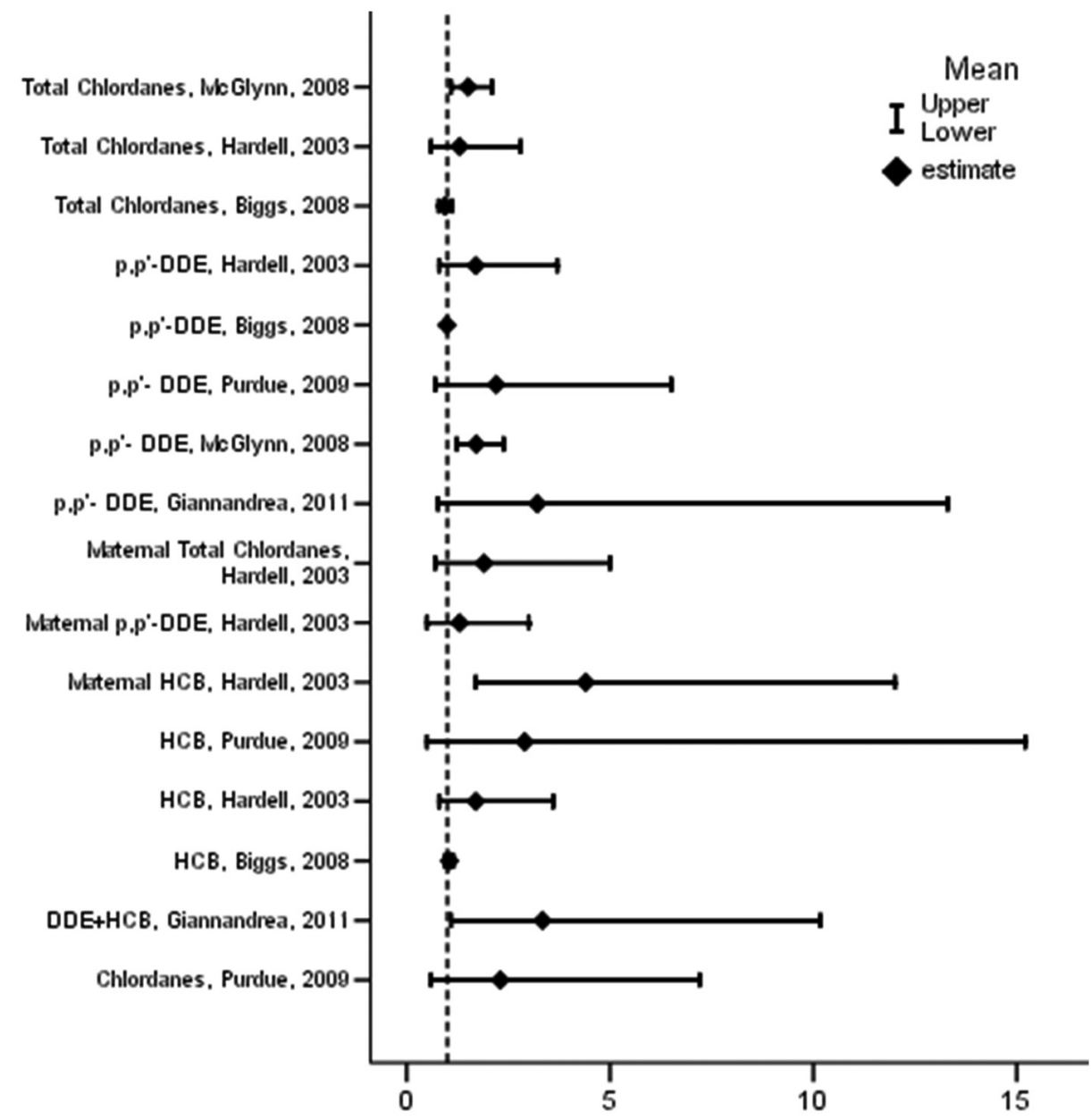

Fig. 2. Summary of studies on the risk of testicular cancer and exposure to organochlorine compounds in $\mathbf{5}$ epidemiological studies. Estimated OR and $95 \% \mathrm{Cl}$. 
the long-tem effects of these compounds, mainly organochlorine pesticides, on human health. In addition to acute poisonings, there is a wide range of diseases that have been suggested to be related to chronic exposure to organochlorine pesticide, including cancer, endocrine problems and reproductive disorders (Hanke 2004). The insufficient protection of pregnant agricultural workers is a further source of concern because of the growing evidence that exposure to pesticides may induce reproductive damage and possible detrimental effects in the male offspring (Hanke 2004, Giannandrea et al., 2008). Due to their strong persistence in the environment, they are still ubiquitous contaminants, although measured serum levels have rapidly declined in the developed world in the past few decades as a consequence of their bans (Cook et al., 2011).

\section{Dichloro-diphenyl-trichloroethylene ( $\left.p, p^{\prime}-D D E\right)$}

The agent $p, p^{\prime}-D D E$, a metabolite of DDT, is a potent androgen receptor antagonist, which was commonly used as a pesticide until it was banned in the 1970s-1980s (Cook et al., 2011). To date, five case-control studies have assessed blood concentrations of p,p'-DDE in relation to TC (Fig.2). The results were indicative of a positive association in four of the five studies. The case-control study (49 cases, 51 controls) nested within the Norwegian Janus Serum Bank cohort (Purdue et al., 2009) detected very high levels of $p, p$ '-DDE using pre-diagnostic blood samples. The U.S. Servicemen's Testicular Tumor Environmental and Endocrine Determinant (STEED) Study, a large case-control investigation of TC ( 754 cases, 928 controls) conducted among U.S. servicemen, found elevated pre-diagnostic concentrations of p,p'-DDE among cases versus controls. In this study, the association was statistically significant in the highest quartile of exposure (OR 1.71, $95 \% \mathrm{Cl} 1.23-2.38$, p trend =0.0002) (McGlynn et al., 2008).

In a Swedish hospital-based study of 58 cases and 61 controls, cases were found to have higher serum levels of $p, p$ - DDE, although the association was not statistically significant (Hardell et al., 2003). Biggs et al., (2008) found no evidence that the risk of TC was associated with serum DDE. Recently, a hospital-based case-control study conducted in Italy found that TC patients had elevated concentrations of $p, p$ - DDE (Giannandrea et al., 2011).

\section{Hexachlorobenzene (HCB)}

The fungicide HCB has been assessed in three studies in relation to TC but none have found evidence for association (Hardell et al., 2003; Biggs et al., 2008; Purdue et al., 2009). Only one study has assessed maternal HCB in relation to TC (Hardell et al., 2003). Among case mothers of the study conducted in Sweden, $\mathrm{HCB}$ yielded an OR of $4.4(95 \% \mathrm{Cl} 1.7-12)$.

\section{Chlordane and its derivates}

Three studies, thus far, have assessed chlordane and its derivates (oxychlordane, trans-nonachlor, cis-nonachlor). In the hospitalbased study conducted in Sweden, investigators found significantly higher serum concentrations of both trans-nonachlor (OR 4.1; 95 $\% \mathrm{Cl} 1.5-11$ ) and cis-nonachlor (OR 3.1; $95 \% \mathrm{Cl} 1.2-7.8$ ) among cases compared with controls (Hardell et al., 2003). The STEED Study, similarly found elevated pre-diagnostic concentrations of chlordane compounds among cases versus controls (McGlynn et al., 2008). In the Janus Serum Bank cohort of Norway, TC cases had elevated concentrations of chlordane compounds (Purdue et al., 2009).

\section{Polychlorinated biphenyls (PCBs)}

PCBs are a class of synthetic, persistent, lipophilic, halogenated aromatic compounds that were widely used in industrial and consumer products for decades before their production was banned in the United States in the late 1970s. PCBs were used in cutting oils, lubricants, and as electrical insulators. As a result of their extensive use and persistence, $\mathrm{PCBs}$ remain ubiquitous environmental contaminants. The general population is exposed primarily through ingestion of contaminated foods (e.g., fish, meat, and dairy products), as PCBs bioaccumulate up the food chain (Hardell et al., 2003). As a result of their persistence and ubiquity, measurable levels of serum $\mathrm{PCBs}$ are found in the majority of the general population. An association between PCBs and TC has been proposed but remains unclear. To date, only three studies have assessed PCB exposure in relation to TC. In the Swedish case-control study (Hardell et al., 2004), no differences in PCB levels between men with or without TC was observed. In maternal comparisons, however, mother of seminoma and nonseminoma cases had significantly higher plasma levels of total PCBs and several congeners than mothers of men without TC (OR 3.8, $95 \% \mathrm{Cl}$ 1.4-10) (Hardell et al., 2004). The STEED study (McGlynn et al., 2008) found consistent inverse associations between PCB congeners and TC. The Janus Cohort Study (Purdue et al., 2009) found epidemiologic evidence that some PCB congeners (99 and 167 in particular) may be associated with TC risk, although the relatively small sample size of this study warrant a cautious interpretation. These preliminary findings suggest that the issue is still open to further research.

\section{Concluding remarks}

$\mathrm{TC}$ is the most common malignancy among young males in the western world. Considerable effort has been expended to date to link variations in incidence in TC rates with reproductive, genetic, endocrine, and environmental factors. Although the incidence of TC has increased over the past 40 years, the reasons of this rise are unclear. Established risk factors for TC include cryptorchidism, family history, and genetic factors. However, these known risk factors cannot account for the majority of cases. In the early 1990s, it was suggested that increase in endogenous estrogen levels during pregnancy and/or exposures to various occupational and environmental estrogenic chemicals such as organochlorine compounds may play a causal role in the etiology of TC. Recent years have witnessed an explosive growth in the research on TC, and scientific research to date show a possible link between pesticides and other environmental exposures with endocrine-disrupting activity and risk of TC, Although suggestive, the available evidence requires further confirmation. Future epidemiologic studies need to improve their methods of measuring human exposures in both prenatal and early life and consider the possible synergistic effect of exposures from environmental xenoestrogens and sex hormones. Finally, further research should also focus on the most appropriate life stages for examining endocrine disruptors and TC risk, assessing the possible additive role from androgen secretion acting during puberty in tumor progression.

\section{References}

ALMSTRUP, K., SONNE, S.B., HOEI-HANSEN, C.E., OTTESEN, A.M., NIELSEN, J.E., SKAKKEBAEK, N.E., LEFFERS, H., and RAJPERT-DE MEYTS, E. (2006) 
From embryonic stem cells to testicular germ cell cancer: should we be concerned? Int. J. Androl. 29: 211-218.

ALTIERI, A., and HEMMINKI, K. (2007). Number of siblings and the risk of solid tumours: a nation-wide study. Br J Cancer. 96: 1755-1759.

ARMSTRONG, B., and DOLL, R. (1975). Environmental factors and cancer incidence and mortality in different countries, with special reference to dietary practices. Int J Cancer. 15: 617-631.

ASCHIM, E.L., GROTMOL, T., TRETLI, S., and HAUGEN, T.B. (2005). Is there an association between maternal weight and the risk of testicular cancer? An epidemiologic study of Norwegian data with emphasis on World War II. Int $\mathrm{J}$ Cancer. 116: 327-330.

BALDUCCI, R., GHIRRI, P., BROWN, T.R., BRADFORD, S., BOLDRINI, A., BOSCHERINI, B., SCIARRA, F., and TOSCANO, V. (1996). A clinician looks at androgen resistance. Steroids. 61: 205-211.

BIGGS, M.L., DAVIS, M.D., EATON, D.L., WEISS, N.S., BARR, D.B., DOODY, D.R., FISH, S., NEEDHAM, L.L., CHEN, C., and SCHWARTZ, S.M. (2008). Serum organochlorine pesticide residues and risk of testicular germ cell carcinoma: a population-based case-control study. Cancer Epidemiol Biomarkers Prev. 17: 2012-2018.

BRAY, F., RICHIARDI, L., EKBOM, A., PUKKALA, E., CUNINKOVA, M., and MØLLER $H$. (2006). Trends in testicular cancer incidence and mortality in 22 European countries: continuing increases in incidence and declines in mortality. Int $J$ Cancer.118: 3099-3111.

BRAUN, M.M., AHLBOM, A., FLODERUS, B., BRINTON, L.A., and HOOVER, R.N. (1995). Effect of twinship on incidence of cancer of the testis, breast, and other sites (Sweden). Cancer Causes Control. 6: 519-524.

CHIA, V.M., QURAISHI, S.M., GRAUBARD, B.I., RUBERTONE, M.V., ERICKSON, R.L., STANCZYK, F.Z., and MCGLYNN, K.A. (2008). Insulin-like growth factor 1, insulin-like growth factor-binding protein 3 , and testicular germ-cell tumor risk. Am J Epidemiol. 167: 1438-1445.

COOK, M.B., AKRE, O., FORMAN, D., MADIGAN, M.P., RICHIARDI, L., and MCGLYNN, K.A. (2009). A systematic review and meta-analysis of perinatal variables in relation to the risk of testicular cancer: experiences of the mother. Int J Epidemiol. 38: 1532-1542.

COOK, M.B., AKRE, O., FORMAN, D., MADIGAN, M.P., RICHIARDI, L., and MCGLYNN, K.A. (2010). A systematic review and meta-analysis of perinatal variables in relation to the risk of testicular cancer: experiences of the son. Int J Epidemiol. 39: 1605-1618

COOK, M.B., TRABERT, B., MCGLYNN, K.A. (2011). Organochlorine compounds and testicular dysgenesis syndrome: human data. Int J Androl. 34: e68-84.

CULIG, Z., HOBISCH, A., BARTSCH, G., and KLOCKER, H. (2000). Androgen receptor: an update of mechanisms of action in prostate cancer. Urol Res.28: 211-219.

DAVIES, T.W., PALMER, C.R., RUJA, E., and LIPSCOMBE, J.M. (1996). Adolescent milk, dairy product and fruit consumption and testicular cancer. $\mathrm{Br} J$ Cancer. 74: 657-660.

DAVIS-DAO, C.A., SIEGMUND, K.D., VANDENBERG, D.J., SKINNER, E.C., COETZEE, G.A., THOMAS, D.C., PIKE, M.C., AND CORTESSIS, V.K. (2011). Heterogenous effect of androgen receptor CAG tract length on testicular germ cell tumor risk: shorter repeats associated with seminoma but not other histologic types. Carcinogenesis. 32: 1238-1243.

DECARLI, A., and LAVECCHIA, C. (1986). Environmental factors and cancer mortality in Italy: correlational exercise. Oncology. 43: 116-126.

DEPUE, R.H., PIKE, M.C., and HENDERSON, B.E. (1983). Estrogen exposure during gestation and risk of testicular cancer. J Natl Cancer. Inst. 71: 1151-1155.

DIECKMANN, K.P., and PICHLMEIER, U. (2004). Clinical epidemiology of testicular germ cell tumors. World J Urol. 22: 2-14.

DIECKMANN, K.P., HARTMANN, J.T., CLASSEN, J., LÜDDE, R., DIEDERICHS, M., and PICHLMEIER, U. (2008). Tallness is associated with risk of testicular cancer: evidence for the nutrition hypothesis. Br J Cancer. 99: 1517-1521.

DONG, C., LÖNNSTEDT, I., and HEMMINKI, K. (2001). Familial testicular cance and second primary cancers in testicular cancer patients by histological type. Eur J Cancer. 37: 1878-1885.

DORGAN JF, JUDD JT, LONGCOPE C, BROWN C, SCHATZKIN A, CLEVIDENCE BA, CAMPBELL WS, NAIR PP, FRANZC, KAHLE L, TAYLOR PR. (1996). Effects of dietary fat and fiber on plasma and urine androgens and estrogens in men: a controlled feeding study. Am J Clin Nutr. 64: 850-855.
FERLIN, A., GANZ, F., PENGO, M., SELICE, R., FRIGO, A.C., FORESTA, C. (2010) Association of testicular germ cell tumor with polymorphisms in estrogen receptor and steroid metabolism genes. Endocr Relat Cancer. 17: 17-25.

FOSTER, W.G., and AGZARIAN, J. (2008). Toward less confusing terminology in endocrine disruptor research. J Toxicol Environ Health B. Crit. Rev. 11: 152-161.

FRANKEL, S., GUNNELL, D.J., PETERS, T.J., MAYNARD, M., and DAVEY SMITH, G. (1998). Childhood energy intake and adult mortality from cancer: the Boyd Orr Cohort Study. Br. Med. J. 316: 499-504.

GANMAA, D., LI, X.M., WANG, J., QIN, L.Q., WANG, P.Y., and SATO, A. (2002) Incidence and mortality of testicular and prostatic cancers in relation to world dietary practices. Int J Cancer. 98: 262-267.

GAROLLA, A., FERLIN, A., VINANZI, C., ROVERATO, A., SOTTI, G., ARTIBANI, W. and FORESTA, C. (2005). Molecular analysis of the androgen receptor gene in testicular cancer. Endocr Relat Cancer.12: 645-655.

GARNER, M.J., BIRKETT, N.J., JOHNSON, K.C., SHATENSTEIN, B., GHADIRIAN P., KREWSKI, D., and CANADIAN CANCER REGISTRIES EPIDEMIOLOGY RESEARCH GROUP. (2003). Dietary risk factors for testicular carcinoma. Int $J$ Cancer.106: 934-941.

GARNER, M.J., TURNER, M.C., GHADIRIAN, P., and KREWSKI, D. (2005). Epidemiology of testicular cancer: an overview. Int J Cancer.116: 331-339.

GIANNANDREA F, SETTIMI L, FIGÀ TALAMANCA I. (2008). The use of persona protective equipment in pregnant greenhouse workers. Occup Med. 58: 52-57.

GIANNANDREA, F. (2009). Correlation analysis of cocoa consumption data with worldwide incidence rates of testicular cancer and hypospadias. Int $J$ Environ Res Public. Health. 6: 568-578.

GIANNANDREA, F., GANDINI, L., PAOLI, D., TURCI, R., and FIGÀ-TALAMANCA, I. (2011). Pesticide exposure and serum organochlorine residuals among testicular cancer patients and healthy controls. J Environ Sci Health. B. 46: 780-787.

GIOVANNUCCI, E., RIMM, E.B., COLDITZ, G.A., STAMPFER, M.J., ASCHERIO, A., CHUTE, C.C., and WILLETT, W.C. (1993). A prospective study of dietary fat and risk of prostate cancer. J Natl Cancer Inst.85: 1571-1579.

GIWERCMAN, A., LUNDIN, K.B., EBERHARD, J., STÅHL, O., CWIKIEL, M., CAVALLIN-STÅHL, and E., GIWERCMAN, Y.L. (2004). Linkage between androgen receptor gene CAG trinucleotide repeat length and testicular germ cell cancer histological type and clinical stage. Eur J Cancer. 40: 2152-2158.

HAMILTON, J.B. (1946). The relationship between common baldness and male sex hormones. Trans. N. Y. Acad. Sci. 8: 101

HANKE W, JUREWICZJ. (2004). The risk of adverse reproductive and developmental disorders due to occupational pesticide exposure: an overview of current epidemiological evidence. Int J Occup Med Environ Health. 17: 223-243.

HARDELL, L., VAN BAVEL, B., LINDSTRÖM, G., CARLBERG, M., DREIFALDT, A.C., WIJKSTRÖM, H., STARKHAMMAR, H., ERIKSSON, M., HALLQUIST, A. and KOLMERT, T. (2003). Increased concentrations of polychlorinated biphenyls, hexachlorobenzene, and chlordanes in mothers of men with testicular cancer Environ Health Perspect.111: 930-934.

HARDELL, L., VAN BAVEL, B., LINDSTRÖM, G., CARLBERG, M., ERIKSSON, M., DREIFALDT, A.C., WIJKSTRÖM, H., STARKHAMMAR, H., HALLQUIST, A., and KOLMERT, T. (2004). Concentrations of polychlorinated biphenyls in blood and the risk for testicular cancer. Int J Androl. 27: 282-290.

HEIMDAL, K., ANDERSEN, T.I., SKREDE, M., FOSSÅ, S.D., BERG, K., and BØRRESEN, A.L. (1995). Association studies of estrogen receptor polymorphisms in a Norwegian testicular cancer population. Cancer Epidemiol Biomarkers Prev. 4: $123-126$.

JAMES, W.H. (2010). Further grounds for abandoning the concept of testicular dysgenesis syndrome: a response to the paper of Akre and Richiardi. Hum Reprod. 25: $1084-1086$

JOFFE, M. (2001). Are problems with male reproductive health caused by endocrine disruption? Occup Environ Med. 58: 281-287.

LERRO, C.C., MCGLYNN, K.A., and COOK, M.B. (2010). A systematic review and meta-analysis of the relationship between body size and testicular cancer. $\mathrm{Br} J$ Cancer. 103: 1467-1474.

LIU, S., SEMENCIW, R., WATERS, C., WEN, S.W., MERY, L.S., MAO, Y. (2000). Clues to the aetiological heterogeneity of testicular seminomas and non-seminomas: time trends and age-period-cohort effects. Int J Epidemiol. 29: 826-831.

LUTKE HOLZIK, M.F., RAPLEY, E.A., HOEKSTRA, H.J., SLEIJFER, D.T., NOLTE, I.M., SIJMONS, R.H. (2004). Genetic predisposition to testicular germ-cell tumours. 
Lancet Oncol. 5: 363-571.

MARTIN, O.V., SHIALIS, T., LESTER, J.N., SCRIMSHAW, M.D., BOOBIS, A.R., and VOULVOULIS, N. (2008). Testicular dysgenesis syndrome and the estrogen hypothesis: a quantitative meta-analysis. Environ Health Perspect. 116: 149-157.

MCGLYNN, K.A., DEVESA, S.S., GRAUBARD, B.I., and CASTLE, P.E. (2005). Increasing incidence of testicular germ cell tumors among black men in the United States. J Clin Oncol. 23: 5757-5761.

MCGLYNN, K.A., QURAISHI, S.M., GRAUBARD, B.I., WEBER, J.P., RUBERTONE, M.V., and ERICKSON, R.L. (2008). Persistent organochlorine pesticides and risk of testicular germ cell tumors. J Nat/ Cancer Inst.100: 663-671.

MCGLYNN, K.A., and COOK, M.B. (2009). Etiologic factors in testicular germ-cell tumors. Future Oncol. 5: 1389-1402.

NATHANSON, K.L., KANETSKY, P.A., HAWES, R., VAUGHN, D.J., LETRERO, R., et al., (2005). The $Y$ deletion $\mathrm{gr} / \mathrm{gr}$ and susceptibility to testicular germ cell tumor. Am J Hum Genet. 77: 1034-1043.

PAIS, V., LEAV, I., LAU, K.M., et al., (2003). Estrogen Receptor- $\beta$ Expression in Human Testicular Germ Cell Tumors. Clin Cancer Res. 9: 4475-4482.

PALMLUND, I. (1996). Exposure to a xenoestrogen before birth: the diethylstilbestrol experience. J. Psychosom Obstet Gynaecol. 17: 71-84.

PHILLIPS, K.P., and TANPHAICHITR, N. (2008).Human exposure to endocrine disrupters and semen quality. $J$ Toxicol Environ Health B Crit Rev. 11: 188-220.

PAULOZZI, L. (1998). Effects of age of diagnosis and latency on the correlation of testicular cancer incidence with fat consumption. Int J Cancer. 78: 527-528.

PENG, X., ZENG, X., PENG, S., DENG, D., ZHANG, J. (2009). The association risk of male subfertility and testicular cancer: a systematic review. PLoS One. 4: e5591.

PETRIDOU, E., ROUKAS, K.I., DESSYPRIS, N.,ARAVANTINOS, G., BAFALOUKOS, D., EFRAIMIDIS, A., PAPACHARALAMBOUS, A., PEKTASIDIS, D., RIGATOS, G., and TRICHOPOULOS, D. (1997). Baldness and other correlates of sex hormones in relation to testicular cancer. Int J Cancer. 71: 982-985.

PURDUE, M.P., DEVESA, S.S., SIGURDSON, A.J., and MCGLYNN, K.A. (2005). International patterns and trends in testis cancer incidence. Int $J$ Cancer. 115: 822-827.

PURDUE, M.P., ENGEL, L.S., LANGSETH, H., NEEDHAM, L.L., ANDERSEN, A., BARR, D.B., BLAIR, A., ROTHMAN, N., and MCGLYNN, K.A. (2009). Prediagnostic serum concentrations of organochlorine compounds and risk of testicular germ cell tumors. Environ Health Perspect. 117: 1514-1519.

RAJPERT-DE MEYTS, E., LEFFERS, H., DAUGAARD, G., ANDERSEN, C.B., PETERSEN, P.M., HINRICHSEN, J., PEDERSEN, L.G., and SKAKKEBAEK, N.E. (2002). Analysis of the polymorphic CAG repeat length in the androgen receptor gene in patients with testicular germ cell cancer. Int J Cancer. 102: 201-204.

REPPING, S., SKALETSKY, H., BROWN, L., VAN DAALEN, S.K., KORVER, C.M., PYNTIKOVA, T., KURODA-KAWAGUCHI, T., DE VRIES, J.W., OATES, R.D., SILBER, S., VAN DER VEEN, F., PAGE, D.C., and ROZEN, S. (2003). Polymorphism for a 1.6-Mb deletion of the human $\mathrm{Y}$ chromosome persists through balance between recurrent mutation and haploid selection. Nat Genet. 35: 247-251.

RICHIARDI, L., AKRE, O., LAMBE, M., GRANATH, F., MONTGOMERY, S.M., and EKBOM, A. (2004). Birth order, sibship size, and risk for germ-cell testicular cancer. Epidemiology. 15: 323-329.
RICHIARDI, L., AKRE, O. (2005). Fertility among brothers of patients with testicular cancer. Cancer Epidemiol Biomarkers Prev. 14: 2557-2562.

RICHIARDI, L., PETTERSSON, A., and AKRE, O. (2007). Genetic and environmental risk factors for testicular cancer. Int J Androl. 30: 230-40; discussion 240-241.

SARTOR, O., ZHENG, Q., and EASTHAM, J.A. (1999). Androgen receptor gene CAG repeat length varies in a race-specific fashion in men without prostate cancer. Urology. 53: 378-380.

SHARPE, R.M., SKAKKEBAEK, N.E. (1993). Are oestrogens involved in falling sperm counts and disorders of the male reproductive tract? Lancet. 341: 1392-1395.

SHARPE, R.M. (2003). The 'oestrogen hypothesis': where do we stand now? Int J Androl. 26: 2-15

SIGURDSON, A.J., CHANG, S., ANNEGERS, J.F., DUPHORNE, C.M., PILLOW, P.C., AMATO, R.J., HUTCHINSON, L.P., SWEENEY, A.M., and STROM, S.S. (1999). A case-control study of diet and testicular carcinoma. Nutr Cancer. 34: 20-26.

SKAKKEBAEK, N.E., BERTHELSEN, J.G., GIWERCMAN, A., MÜLLER, J. (1987). Carcinoma-in-situ of the testis: possible origin from gonocytes and precursor of all types of germ cell tumours except spermatocytoma. Int J Androl. 10: 19-28.

SKAKKEBAEK, N.E., RAJPERT-DE MEYTS, E., and MAIN, K.M. (2001). Testicular dysgenesis syndrome: an increasingly common developmental disorder with environmental aspects. Hum Reprod. 16: 972-978.

STANG, A., AHRENS, W., BAUMGARDT-ELMS, C., STEGMAIER, C., MERZENICH H., DE VRESE, M., SCHREZENMEIR, J., and JÖCKEL, K.H. (2006). Adolescent milk fat and galactose consumption and testicular germ cell cancer. Cancer Epidemiol Biomarkers Prev. 15: 2189-2195.

STORGAARD, L., BONDE, J.P., OLSEN, J. (2006). Male reproductive disorders in humans and prenatal indicators of estrogen exposure. A review of published epidemiological studies. Reprod Toxicol. 21: 4-15.

STROHSNITTER, W.C., NOLLER, K.L., HOOVER, R.N., ROBBOY, S.J., PALMER, J.R., TITUS-ERNSTOFF, L., KAUFMAN, R.H., ADAM, E., HERBST, A.L., and HATCH, E.E. (2001). Cancer risk in men exposed in utero to diethylstilbestrol. $J$ Natl Cancer Inst. 93: 545-551.

SWERDLOW, A.J., DE STAVOLA, B.L., SWANWICK, M.A., MANGTANI, P., MACONOCHIE, N.E. (1999). Risk factors for testicular cancer: a case-control study in twins. Br J Cancer. 80: 1098-1102.

TOPPARI, J., LARSEN, J.C., CHRISTIANSEN, P., GIWERCMAN, A., GRANDJEAN, P., GUILLETTE, L.J. JR, JÉGOU, B., JENSEN, T.K., JOUANNET, P., KEIDING, N., LEFFERS, H., MCLACHLAN, J.A., MEYER, O., MÜLLER, J., RAJPERT-DE MEYTS, E., SCHEIKE, T., SHARPE, R., SUMPTER, J., SKAKKEBAEK, N.E. (1996). Male reproductive health and environmental xenoestrogens. Environ Health Perspect. 104: 741-803.

TRABERT, B., SIGURDSON, A.J., SWEENEY, A.M., AMATO, R.J., STROM, S.S., and MCGLYNN, K.A. (2011). Baldness, acne and testicular germ cell tumours. Int J Androl. 34: e59-67.

UAUY, R., SOLOMONS, N. (2005). Diet, nutrition, and the life-course approach to cancer prevention. J Nutr. 135: 2934S-2945S.

VELDHUIS, J.D., ROEMMICH, J.N., RICHMOND, E.J., ROGOL, A.D., LOVEJOY, J.C. SHEFFIELD-MOORE, M., MAURAS, N., BOWERS, C.Y. (2005). Endocrine control of body composition in infancy, childhood, and puberty. Endocr Rev. 26: 114-146. 


\section{Further Related Reading, published previously in the Int. J. Dev. Biol.}

\section{Germline stem cells and sex determination in Hydra}

Chiemi Nishimiya-Fujisawa and Satoru Kobayashi

Int. J. Dev. Biol. (2012) 56: 499-508

Impaired meiotic competence in putative primordial germ cells produced from mouse embryonic stem cells

Marianna Tedesco, Donatella Farini and Massimo De Felici

Int. J. Dev. Biol. (2011) 55: 215-222

In vitro germ cell differentiation during sex differentiation in a teleost fish

Tohru Kobayashi

Int. J. Dev. Biol. (2010) 54: 105-111

Differentiation of mouse primordial germ cells into female or male germ cells

N Nakatsuji and S Chuma

Int. J. Dev. Biol. (2001) 45: 541-548

The meiotic specific synaptonemal complex protein SCP3 is expressed by female and male primordial germ cells of the mouse embryo

A D Di Carlo, G Travia and M De Felici

Int. J. Dev. Biol. (2000) 44: 241-244

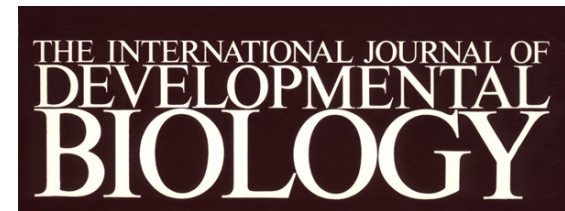

Volume 37 No. 1

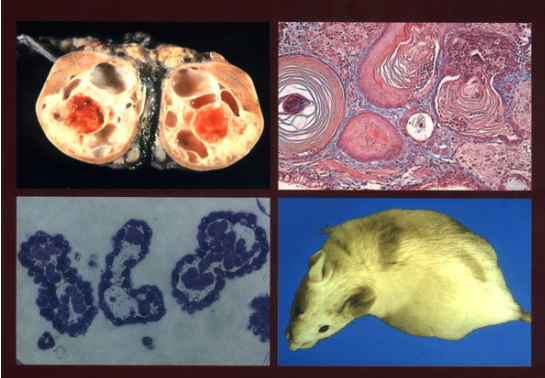

Developmental Aspects of Neoplasia
5 yr ISI Impact Factor (2011) $=2.959$
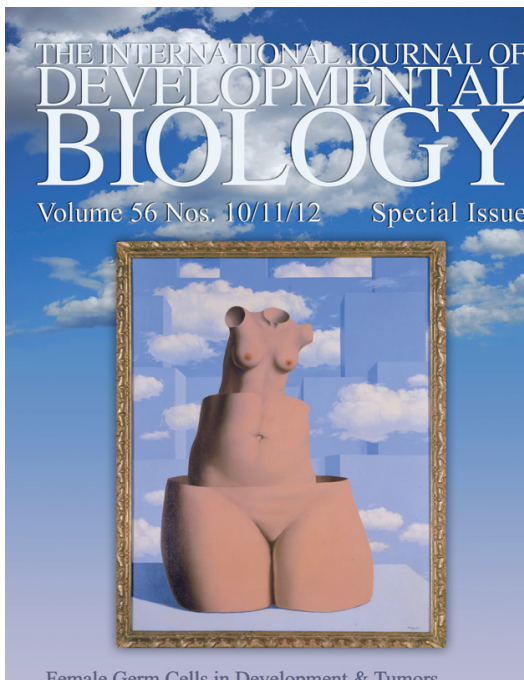
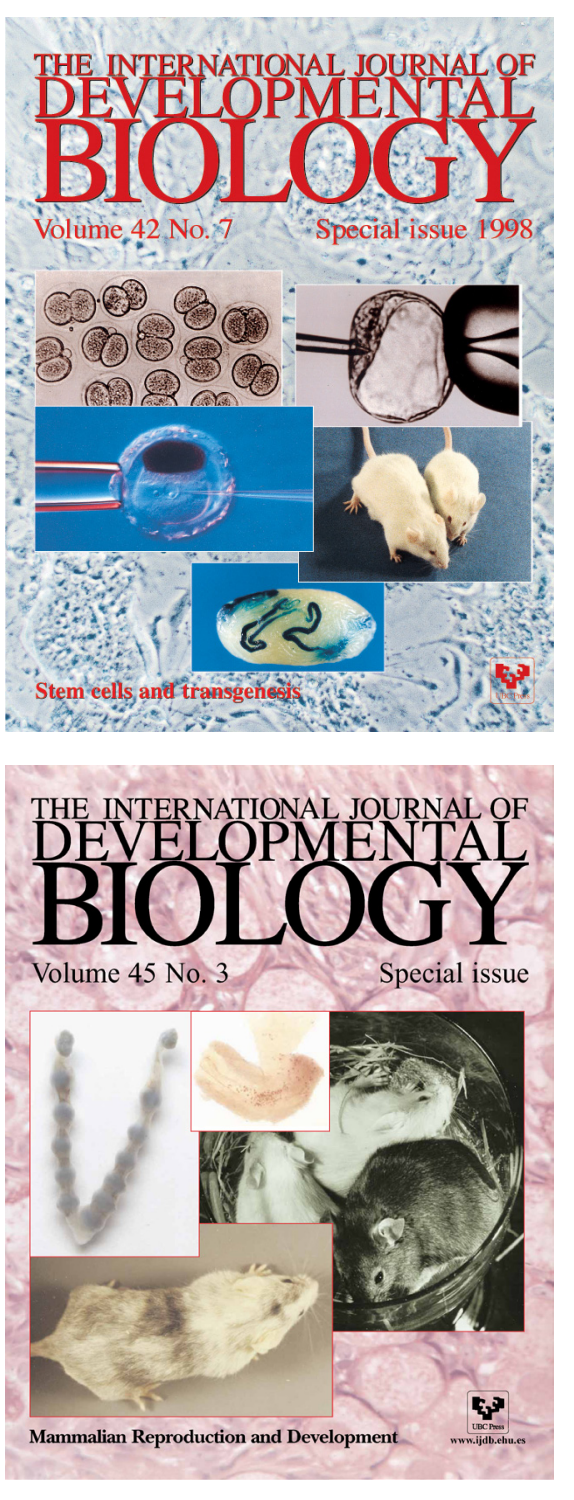